\title{
BMJ Open Housing index, urbanisation level and lifetime prevalence of depressive and anxiety disorders: a cross-sectional analysis of the Colombian national mental health survey
}

\author{
Esther de Vries, ${ }^{1}$ Carlos Javier Rincon, ${ }^{1}$ Nathalie Tamayo Martínez, ${ }^{1}$ \\ Nelcy Rodriguez, ${ }^{1}$ Henning Tiemeier, ${ }^{2}$ Johan P Mackenbach, ${ }^{3}$ \\ Carlos Gómez-Restrepo, ${ }^{1,4}$ Carol C Guarnizo-Herreño ${ }^{5,6}$
}

To cite: de Vries E, Rincon CJ, Tamayo Martínez N, et al. Housing index, urbanisation level and lifetime prevalence of depressive and anxiety disorders: a crosssectional analysis of the Colombian national mental health survey. BMJ Open 2018;8:e019065. doi:10.1136/ bmjopen-2017-019065

- Prepublication history and additional material for this paper are available online. To view these files, please visit the journal online (http://dx.doi. org/10.1136/bmjopen-2017019065).

Received 10 August 2017 Revised 21 December 2017 Accepted 4 January 2018
Check for updates

For numbered affiliations see end of article.

Correspondence to

Dr Esther de Vries;

estherdevries@javeriana.edu.co

\section{ABSTRACT}

Objectives To study socioeconomic inequalities in mental health in rural and urban Colombia, a country with a history of internal conflict and large socioeconomic inequalities. Recent survey data are available to study this understudied topic in a middle-income country. Methods Using data from 9656 respondents from the 2015 Colombian Mental Health survey, we investigated the association between lifetime prevalence of depressive and anxiety disorders and quality of dwellings and access to public services housing score (HS). We calculated the relative index of inequality (RII) and slope index of inequality (SII) for HS in urban and rural areas, adjusting for potential confounders and mediating factors.

Outcomes The lifetime prevalence of anxiety and depression (combined) was $9.6 \%$ in urban versus $6.9 \%$ in rural areas $(p<0.001)$. HS was not associated with prevalence of anxiety and depression in urban settings, whereas a higher HS (poorer housing quality) was associated with fewer mental disorders in rural areas in both univariate and multivariate models (multivariate $\mathrm{RII}_{\text {urban }} 0.96$ (95\% Cl 0.51 to 1.81$) ; \mathrm{RI}_{\text {rural }} 0.11(95 \% \mathrm{Cl}$ 0.04 to 0.32$)$ ). In rural areas, the prevalence of mental health problems was $12 \%$ points lower in persons living in the poorest quality dwellings than in those living in high-quality dwellings (SII $-0.12(95 \% \mathrm{Cl}-0.18$ to $-0.06)$ ). Interestingly, within rural areas, persons living in 'populated centres' (small towns, villages) had a higher lifetime prevalence of any mental health disorder (9.8\% (95\% Cl 6.9 to 13.6)) compared with those living in more isolated, dispersed areas $(6.0 \%(95 \% \mathrm{Cl} 4.6$ to 7.7)).

Interpretation In rural Colombia, those living in the poorest houses and in dispersed areas had a lower prevalence of mental health problems. Further understanding of this phenomenon of a seemingly inverse association of prevalence of mental disorders with poverty and/or urbanisation in rural areas is needed. Particularly, considering the progressive urbanisation process in Colombia, it is important to monitor mental health in populations migrating to the cities.
Strengths and limitations of this study

- The analysis is based on a nationally representative sample of 9656 adult respondents.

- The survey used validated instruments to measure prevalence of various mental health problems.

- This study adds to the literature on mental health inequalities in rural and urban settings in low-income and middle-income countries.

- Data from 1214 respondents were excluded from the analysis due to incomplete information.

- Because of the relatively low 12 month prevalence, only lifetime prevalence of mental disorders was used as outcome.

\section{INTRODUCTION}

Although there is a growing body of evidence of the association between socioeconomic indicators and mental health in low-income and middle-income countries (LMIC), this issue has been mostly investigated in high-income country (HIC) populations. ${ }^{1}$ Most of the studies from LMICs show a positive association between poverty and mental health problems, but some report no or negative associations. $^{2} 3$ Variables like food insecurity, housing, social class and financial stress are consistently associated with mental health disorders, while income, employment, education and consumption are more equivocal. $^{24-10}$ Moreover, a recent literature review found that the evidence of the relationship between socioeconomic factors and mental health in LMICs is very mixed with results varying according to the socioeconomic measure used and the hypothesised directionality of effects. ${ }^{1}$ That review and certain specific analyses have also shown that poverty alleviation interventions based only 
on economic aids for the poor might not be sufficient enough to have a significant impact on their mental health. ${ }^{11}$ Most studies of LMICs populations report a positive association between mental health problems and poverty-indirectly related to residential crowding and awareness of hardship compared with others-which can affect mental health. ${ }^{311} 12$ Few studies investigating the association between mental health and socioeconomic position have analysed rural populations in LMICs.

Studies of population mental health and patterns of inequalities comparing urban and rural settings generally document a higher prevalence of affective and anxiety disorders in urban settings in both $\mathrm{HIC}^{13}$ and LMIC, ${ }^{14}{ }^{15}$ but the difference in rural settings is not always statistically significant. Data from the 2015 Colombian Mental Health Survey (ENSM IV) showed a higher lifetime prevalence of mental health disorders in urban than rural areas. ${ }^{16}$ Some proposed mechanisms that may explain this higher prevalence in urban settings are a weaker social support network and more social pressure (more informal work, risks of losing jobs, pressure to comply with working hours, etc) than in rural settings, ${ }^{3}$ but these mechanisms have not been investigated to date.

Since socioeconomic inequalities in mental health are an important but largely under-researched topic in LMIC, we set out to investigate if socioeconomic gradients in mental health problems exist in Colombia. Given that the prevalence of mental health problems is usually higher in urban areas, we performed a stratified analysis by urban and rural settings. The Mental Health survey (ENSM IV) data offer a unique opportunity to study mental health problems in urban and rural settings in association with housing characteristics and access to public services as well as other indicators of socioeconomic status. This nationally representative survey was therefore chosen as the data source for this analysis. We are not aware of previous studies examining mental health inequalities in LMICs that stratify the population by urban/rural area of residence.

\section{METHODS}

\section{Data source and study sample}

We analysed data from the 2015 Colombian ENSM IV, which measures aspects of mental health and access to and use of mental health services among people aged 7 years and over. ${ }^{17}$ The survey had a multistage cluster and probabilistic sample design, which provides representative data at national and regional levels. From every eligible sampled household, an individual aged $\geq 12$ years was randomly selected and invited to participate; if the household included children aged 7-11 years, one of them was also selected and invited to participate. Further details of the survey's design are provided elsewhere. ${ }^{1617}$ The survey collected data from a sample of 15351 individuals, of which 10870 were adults (18+ years). The overall household response rate was $97.4 \%$ and the individual response rate was $95.1 \%$. This high response rate is not uncommon for Colombian population surveys, which are usually conducted by household visits and face-to-face interviews. ${ }^{18}{ }^{19}$ We performed complete-case analyses, so only adults with complete information for measures of mental health disorders, housing characteristics and all other covariates were included in the analytical sample. Therefore, 1214 adults without responses or with missing information on any of the study variables were excluded. For all variables and for the main analyses, the rate of missing information was less than $5 \%$. The final sample used for our analyses was 9656 individuals: 7644 in urban and 2012 in rural areas.

To evaluate if missing data influenced the results, we performed an additional analysis, with multiple imputation for the following variables: educational level (103 data missing), armed conflict (106), use of sanitary (543), electricity, sewage, water and garbage services (17) and prevalence of any mental health disorder (466).

\section{Study measures}

Mental health disorders

Mental health disorders were assessed using the WHO Composite International Diagnostic Interview with computer-assisted personal interview methodology (CIDI3.0-CAPI). The CIDI-3.0 is a structured questionnaire on the presence, intensity and persistence of clusters of psychiatric symptoms ${ }^{20}$ that provides mental disorder diagnoses according to the Diagnostic and Statistical Manual of Mental Disorders, 4th Edition (DSM-IV) diagnostic criteria, ${ }^{4}$ the mental disorders captured include major and minor depressive disorders, dysthymia, bipolar affective disorder, other bipolar affective disorders (including type II), generalised anxiety disorder, panic disorder and social phobia. For this analysis, a binary indicator was created to identify adults who had any mental disorder during their lifetime.

\section{Housing score and socioeconomic position (SEP)}

Colombia has a long and recent history of violence, one of the largest socioeconomic inequalities worldwide and a relatively large informal economy. ${ }^{21}{ }^{22}$ In countries with large informal economies, traditional indicators of SEP such as formal income or educational level are less indicative for living conditions than in formal economies. Factors like housing quality and access to public services can be alternative indicators in such situations and have been increasingly used in LMIC. ${ }^{23}$ In Colombia, if a person lives in a house that is connected to public services such as sewage systems, electricity and drinking water and the house is made of good quality materials, his/her SEP is probably higher and this person probably lives in a more urbanised area than someone who lives in a house without connection to public services or made of inferior building materials.

Our main measure of SEP was the housing score, an indicator of poor housing characteristics, which was based on the Household Wealth Index (HWI), an index extensively used in Demographic Health Surveys (DHS) in LMICs. ${ }^{24}$ 
This asset-based index includes housing characteristics, publicly provided services and durable consumer goods. The ENSM IV was composed of nine questions written in the same way as those included in the Colombian DHS to derive the HWI. The majority of variables from the ENSM IV were employed in this study: type of toilet (shared or private and connection/lack of connection to sewage system), principal material of floor and walls, electricity supply, general access to sewage systems, garbage collection, bath or shower within the house and type of access to water. Table 1 describes the distribution of these variables for urban and rural areas. We dichotomised these variables following criteria from the EquityTool-DHS wealth index ${ }^{25}$ to identify poor housing conditions. We derived the indicator (housing score) for the number of poor housing characteristics and categorised it into five categories: $0,1-2,3-4,5-6$ and 7-9 'poor' characteristics present in a house-a higher score indicated poorer housing quality. This categorisation was based on the distribution of the variable in the analytical sample in rural areas. The ENSM IV survey did not include questions about ownership of durable consumer goods such as radio, television, fridge or phone.

\section{Other covariates}

Age, gender, marital status and geographical location (region) were included as covariates, given their relationship with mental health and the housing score. These variables alongside educational attainment and affiliation with the Colombian social security system were considered to be potential confounders of the relationship between SEP (housing score) and mental health problems. In the analysis, we included age as a continuous variable and included the other variables using the categories shown in table 2. Affiliation with the social security system was categorised taking into account features of the funding scheme and details of the social security system in Colombia, which are provided elsewhere. ${ }^{26} 27$ Experience of consequences from the armed internal conflict in Colombia, family dysfunction and social support were thought to be potential mediators between SEP and mental health and were also included in the models to assess their potential role in the association of interest. Experience with the armed conflict was categorised as yes / no; family dysfunction was categorised using the APGAR instrument ${ }^{28}$ in four categories: no, low, moderate and severe family dysfunction and social support ('How often can you talk to someone about your problems or difficulties or ask for advice?') was categorised as always, almost always, often and never. The classification of covariates as potential confounders or mediators was theoretically oriented and based on evidence showing the hypothesised relationships. ${ }^{29} 30$

We analysed the data separately for urban and rural settings, defined in accordance with the national statistics office (DANE) as follows: urban areas include all capital cities and municipalities with a central administrative office (ex: town hall), rural areas are characterised by
Table 1 Distribution of the variables related to the type of housing, stratified by rural/urban residence

\begin{tabular}{|c|c|c|}
\hline Variables & Urban, $\mathbf{N}(\%)$ & Rural, N (\%) \\
\hline \multicolumn{3}{|c|}{ Main material used for the exterior walls of the dwelling } \\
\hline $\begin{array}{l}\text { Brick, stone or } \\
\text { polished wood }\end{array}$ & 7181 (93.9) & $1231(61.2)$ \\
\hline Mud or clay walls & $77(1.0)$ & $174(8.6)$ \\
\hline Daub walls & $92(1.2)$ & $259(12.9)$ \\
\hline $\begin{array}{l}\text { Rough wood, } \\
\text { planks, board }\end{array}$ & $228(3.0)$ & $290(14.4)$ \\
\hline $\begin{array}{l}\text { Prefabricated } \\
\text { materials }\end{array}$ & $32(0.4)$ & $27(1.3)$ \\
\hline $\begin{array}{l}\text { Guadua, cane, } \\
\text { mats, other plant } \\
\text { materials }\end{array}$ & $9(0.1)$ & $26(1.3)$ \\
\hline $\begin{array}{l}\text { Zink, fabric, } \\
\text { canvas, } \\
\text { cardboard, can }\end{array}$ & $24(0.3)$ & $4(0.2)$ \\
\hline $\begin{array}{l}\text { Dwelling does not } \\
\text { have walls }\end{array}$ & $1(0.0)$ & $1(0.0)$ \\
\hline \multicolumn{3}{|c|}{ Main material of the floors } \\
\hline $\begin{array}{l}\text { Carpet or wall-to- } \\
\text { wall rug }\end{array}$ & $45(0.6)$ & $1(0.0)$ \\
\hline $\begin{array}{l}\text { Polished and } \\
\text { lacked wood }\end{array}$ & $83(1.1)$ & $6(0.3)$ \\
\hline Marble & $75(1.0)$ & $1(0.0)$ \\
\hline Tiles, vinyl, brick & $5298(69.3)$ & $497(24.7)$ \\
\hline $\begin{array}{l}\text { Unpolished wood, } \\
\text { planks, other } \\
\text { plant material }\end{array}$ & $151(2.0)$ & $150(7.5)$ \\
\hline Cement, gravel & $1845(24.1)$ & $1043(51.8)$ \\
\hline Soil, sand & $147(1.9)$ & $314(15.6)$ \\
\hline
\end{tabular}

With what type of sanitary system is this dwelling equipped?

$\begin{array}{lcc}\begin{array}{l}\text { Toilet connected } \\ \text { to sewage system }\end{array} & 7046(92.2) & 592(29.4) \\ \begin{array}{l}\text { Toilet connected } \\ \text { to septic tank }\end{array} & 486(6.4) & 1137(56.5) \\ \begin{array}{l}\text { Unconnected } \\ \text { toilet }\end{array} & 89(1.2) & 186(9.2)\end{array}$

$\begin{array}{lrr}\text { Latrine } & 16(0.2) & 96(4.8) \\ \begin{array}{l}\text { Sanitary above } \\ \text { river or other } \\ \text { open water }\end{array} & 7(0.1) & 1(0.0) \\ \text { source } & & \end{array}$

\begin{tabular}{|c|c|c|}
\hline The sanitary is... & 76440 & 20120 \\
\hline $\begin{array}{l}\text { Exclusively } \\
\text { for use by } \\
\text { inhabitants of the } \\
\text { household }\end{array}$ & 7110 (93.0) & $1861(92.5)$ \\
\hline $\begin{array}{l}\text { Shared with } \\
\text { persons from } \\
\text { other households }\end{array}$ & $534(7.0)$ & $151(7.5)$ \\
\hline \multicolumn{3}{|c|}{ This dwelling has a shower or sprinkler? } \\
\hline
\end{tabular}

Continued 
Table 1 Continued

\begin{tabular}{ccc}
\hline Variables & Urban, N (\%) & Rural, N (\%) \\
\hline Yes & $6934(90.7)$ & $1252(62.2)$ \\
No & $710(9.3)$ & $760(37.8)$
\end{tabular}

Drinking water and water for preparing food is mainly obtained from

\begin{tabular}{|c|c|c|}
\hline Public aqueduct & 7023 (91.9) & $639(31.8)$ \\
\hline $\begin{array}{l}\text { Local community } \\
\text { aqueduct }\end{array}$ & $140(1.8)$ & $772(38.4)$ \\
\hline Well with pump & $141(1.8)$ & $128(6.4)$ \\
\hline $\begin{array}{l}\text { Well without } \\
\text { pump }\end{array}$ & $40(0.5)$ & $111(5.5)$ \\
\hline Rainwater & $59(0.8)$ & $22(1.1)$ \\
\hline $\begin{array}{l}\text { River, brook, } \\
\text { spring }\end{array}$ & $17(0.2)$ & $289(14.4)$ \\
\hline Tank truck & $38(0.5)$ & $22(1.1)$ \\
\hline $\begin{array}{l}\text { Bottle water or } \\
\text { water from a bag }\end{array}$ & $186(2.4)$ & $29(1.4)$ \\
\hline \multicolumn{3}{|l|}{ Has electricity } \\
\hline No & $27(0.4)$ & $31(1.5)$ \\
\hline Yes & 7617 (99.6) & $1981(98.5)$ \\
\hline \multicolumn{3}{|c|}{ Is connected to an aqueduct } \\
\hline No & $427(5.6)$ & $629(31.3)$ \\
\hline Yes & 7217 (94.4) & $1383(68.7)$ \\
\hline \multicolumn{3}{|c|}{ Connected to sewage system } \\
\hline No & $682(8.9)$ & $1432(71.2)$ \\
\hline Yes & 6962 (91.1) & $580(28.8)$ \\
\hline \multicolumn{3}{|c|}{ System for garbage recollection } \\
\hline No & $261(3.4)$ & $1339(66.6)$ \\
\hline Yes & 7383 (96.6) & $673(33.4)$ \\
\hline
\end{tabular}

more dispersed dwellings, a general lack of street name systems, etc. Within rural areas, there is a wide variation in 'level of urbanisation', with both small villages and/or isolated houses.

\section{Statistical analysis}

All analyses were stratified by urban/rural setting, as we were interested not only in assessing whether the magnitude of inequalities differed between urban and rural areas but also in exploring the potential role of covariates in both settings. Moreover, because in the Colombian context there are important rural/urban differences, such as socioeconomic conditions and experiences with armed internal conflict, we sought to characterise inequalities separately in these two areas.

We estimated the lifetime prevalence of mental disorders by categories of the housing score and derived the relative index of inequality (RII) and the slope index of inequality (SII) to measure relative and absolute inequalities, while accounting for the distribution of the population across all socioeconomic groups. By doing this, we removed differences in the size of socioeconomic groups as source of variation in the magnitude of health inequalities. ${ }^{31}{ }^{32}$ For both urban and rural areas, the RII was calculated using logistic regression models, adjusting for age, sex, marital status and region. The RII is the ratio between the prevalence of mental disorders in areas with the worst housing characteristics (ranked 1 on the housing scale) and areas with the best housing characteristics (ranked 0 of the housing score) and can thus be interpreted as the prevalence OR of mental disorders between those with the worst and those with the best housing characteristics in the population. ${ }^{32}{ }^{33}$ Values of RII $>1$ indicate a higher prevalence of mental disorders among those with worse housing characteristics. We also calculated the SII, which is the difference between the predicted values at both extremes of the housing score and expresses the absolute difference in prevalence of mental health problems between the population at the top and the bottom of the housing score distribution.

Considering the requirements of the RII and SII, the categorical indicator for the housing score was introduced as a quantitative variable with values between 0 and 1 according to the distribution in the analytical sample. We included all the above-mentioned covariates in the RII model to explore their role in the observed health inequalities.

To evaluate the effect of missing data on our main results, we imputed missing data for educational level, armed conflict, prevalence of any mental health disorder and use of sanitary, electricity, sewage, water and garbage services. All were imputed using chained equations $(\mathrm{M}=5)^{34}$ in a logistic regression model for all variables except educational level (ordinal logistic regression), using the mi command in Stata V.14. Independent variables (without missing data) included in these models were age, sex, region, urban/rural area of residence, marital status and family dysfunction. The analyses for the main model were repeated for the imputed data (including the expansion factor). These analyses with an imputed sample were aimed at evaluating the consistency of our findings, and therefore, estimates presented in this paper are from complete-case analyses. In addition, as estimates from the imputed sample showed very narrow CIs, we concluded that reporting results from the original data was a more conservative approach.

All estimates took into account sample weighting to obtain population-based estimates. All analyses were conducted in Stata V.14.

\section{RESULTS}

The weighted lifetime prevalence of any mental disorder was $9.6 \%$ (95\% CI $8.5 \%$ to $10.8 \%$ ) in urban areas versus $6.9 \%$ (95\% CI $5.6 \%$ to $8.4 \%$ ) in rural areas. Table 2 shows the distribution of sociodemographic characteristics of the respondents by urban/rural area of residence. The distribution of marital status, education level, experience with armed conflict and type of affiliation with the 
Table 2 Description of the sample

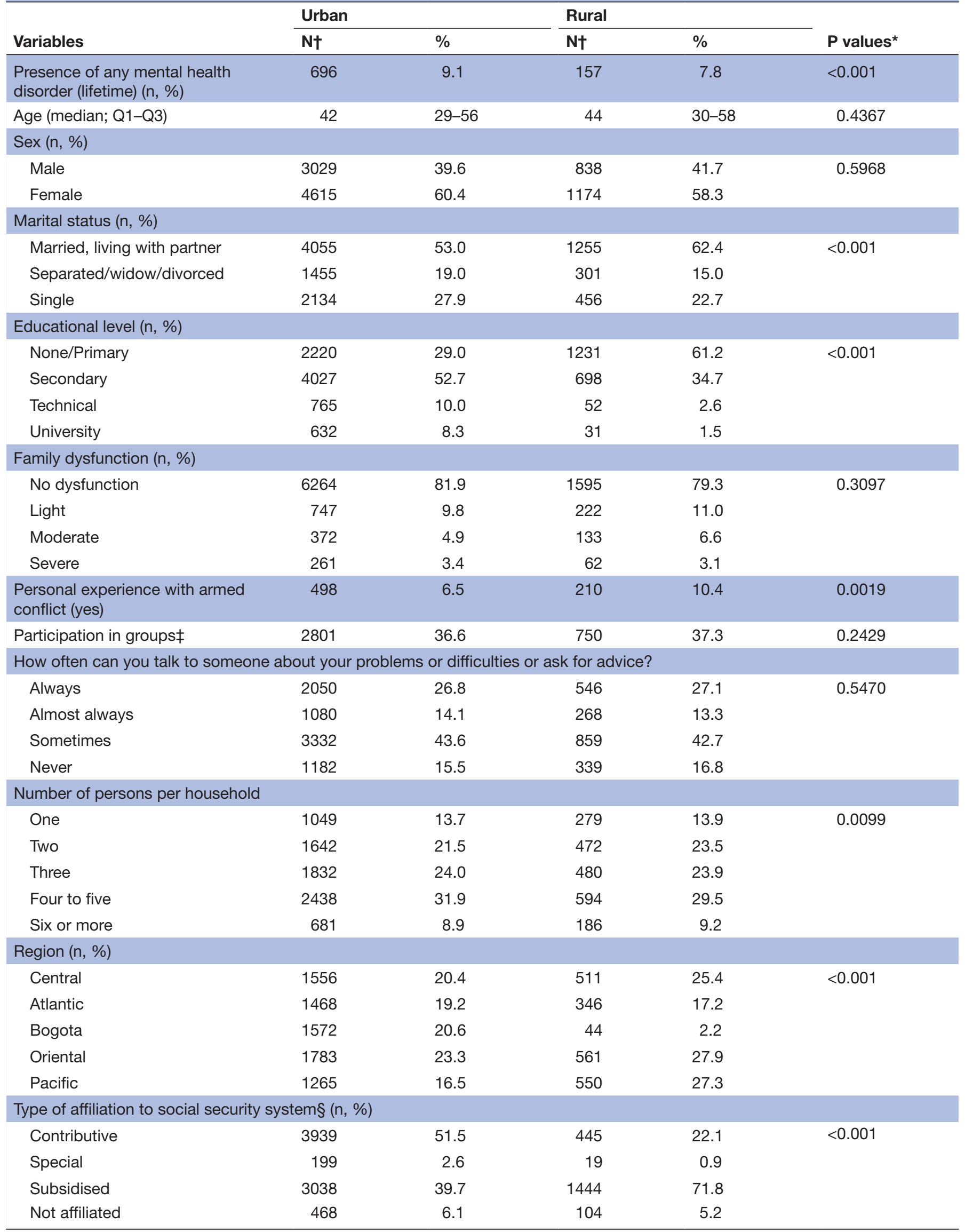


Table 2 Continued

\begin{tabular}{|c|c|c|c|c|c|}
\hline \multirow[b]{2}{*}{ Variables } & \multicolumn{2}{|l|}{ Urban } & \multicolumn{2}{|l|}{ Rural } & \multirow[b]{2}{*}{ P values* } \\
\hline & $\mathbf{N \dagger}$ & $\%$ & $\mathbf{N} †$ & $\%$ & \\
\hline \multicolumn{6}{|c|}{ Housing score (higher=poorer quality) } \\
\hline $1($ sum=1, 2) & 2225 & 29.1 & 300 & 14.9 & \multirow{3}{*}{$<0.001$} \\
\hline $2($ sum=3, 4) & 587 & 7.7 & 401 & 19.9 & \\
\hline $4(\mathrm{sum}=7,8,9)$ & 77 & 1.0 & 534 & 26.5 & \\
\hline
\end{tabular}

${ }^{*} P$ values of independence test corrected by the survey expansion factor.

$\dagger$ Numbers represent absolute numbers from the survey, \% are prevalence weighted for expansion factor of the survey. †Religious, sports, political, cultural, community, ecological, ethnic, youth, health groups.

$\S$ The contributive regime includes those in formal employment or independent jobs with economic capacity to pay a monthly fee; special regime includes armed forces, workers in the petroleum industry and teachers in the public sector; in the subsidised regime are those classified as 'poor' and their insurance fee is paid by the government and not affiliated are those without health insurance.

social security system differed between urban and rural areas, as did region of residence. In rural areas, there was an inverse gradient with lower lifetime prevalence of mental health disorders as quality of housing conditions decreased (table 3).

In both univariate and multivariate analyses corrected for age, sex, region and marital status, results from the RII revealed a non-significant association between the housing score and prevalence of mental disorders in urban areas: RII ${ }_{\text {univariate }} 0.86(95 \%$ CI 0.50 to 1.48 ), RII $I_{\text {multivariate }} 1.13$ (95\% CI 0.65 to 1.95 ). On the contrary, in rural areas, there was a strong and highly significant association in both univariate and multivariate analyses: $\mathrm{RII}_{\text {univariate }} 0.16$ (95\% CI 0.07 to $0.38)$, RII multivariate 0.19 (95\% CI 0.08 to 0.49$)$-where higher scores (ie, fewer public facilities available and lower quality products used for construction) were associated with fewer mental disorders. Absolute differences in the same multivariate model indicate a 9.4\% points lower prevalence of mental health problems in the population with the worst housing score in rural settings, SII -0.09 (95\% CI -0.15 to -0.04$)$ (tables 4 and 5). In a multivariate model, taking into account educational level, family dysfunction, social support, experience with armed conflict and type of affiliation with the social security system, the housing score remained non-significant (RII $0.9695 \%$ CI 0.51 to 1.81 ) in urban areas, while in rural areas the RII was strengthened: 0.11 (95\% CI 0.04 to 0.32$)$, illustrating a 'protective' effect of living in poor housing conditions (table 4 ). The difference in absolute terms translates to a $12 \%$ points lower prevalence of mental health problems in rural area with the worst housing scores (SII $-0.12(95 \%$ CI -0.18 to -0.06$)$ ). Other variables in the model showed the expected association with mental health disorders in both rural and urban areas; often statistical significance was only observed in urban areas, likely due to the larger number of respondents in urban areas. Having separated from a partner, having a university degree and not being affiliated with the social security system were all significantly associated with an increased risk of mental disorders in urban areas, as were moderate or severe family dysfunction (in both rural and urban areas), not being able to talk about problems (in urban areas) and having experienced armed conflict (in urban areas). The analyses with imputed data resulted in a more precise, but very similar estimate of the RII for the housing score: in urban areas, the score was 0.92 (95\% CI 0.71 to 1.20$)$ and in rural areas the score was 0.13 (95\% CI 0.10 to 0.18 ) (online Supplementary table 1).

Table 3 Lifetime prevalence of mental health disorders by level of housing score in rural and urban areas

\begin{tabular}{|c|c|c|c|c|}
\hline \multirow{2}{*}{$\begin{array}{l}\text { Socioeconomic position } \\
\text { (housing score) }\end{array}$} & \multicolumn{2}{|l|}{ Urban } & \multicolumn{2}{|l|}{ Rural } \\
\hline & Prevalence (\%) & $95 \% \mathrm{Cl}$ & Prevalence (\%) & $95 \% \mathrm{Cl}$ \\
\hline Level 1 (best housing) & 9.7 & 8.3 to 11.3 & 17.7 & 10.8 to 27.8 \\
\hline Level 2 & 10.1 & 8.4 to 12.1 & 8.0 & 5.2 to 12.2 \\
\hline Level 3 & 8.4 & 4.3 to 15.7 & 5.7 & 3.4 to 9.4 \\
\hline Level 4 & 4.5 & 2.1 to 9.5 & 6.7 & 4.7 to 9.6 \\
\hline Level 5 (worst housing) & 7.1 & 2.1 to 21.4 & 2.5 & 1.5 to 4.2 \\
\hline Total & 9.6 & 8.5 to 10.9 & 6.9 & 5.6 to 8.4 \\
\hline
\end{tabular}


Table 4 Relative index of inequality (RII) (based on housing score)*, in a multivariate model for lifetime prevalence of any mental disorder

\begin{tabular}{|c|c|c|c|c|}
\hline \multirow[b]{4}{*}{ Housing score (RII) } & \multicolumn{4}{|c|}{ Any mental health disorder (lifetime prevalence) } \\
\hline & \multicolumn{2}{|l|}{ Urban } & \multicolumn{2}{|l|}{ Rural } \\
\hline & $\mathbf{R I I} \mathbf{O R}^{*}$ & $95 \% \mathrm{Cl}$ & $\mathbf{R I I} \mathbf{O R}^{*}$ & $95 \% \mathrm{Cl}$ \\
\hline & 0.96 & 0.51 to 1.81 & 0.11 & 0.04 to 0.32 \\
\hline \multicolumn{5}{|c|}{ Demographic characteristics } \\
\hline Age (continuous) & 0.98 & 0.97 to 0.99 & 1.00 & 0.98 to 1.01 \\
\hline $\begin{array}{l}\text { Female sex (reference } \\
\text { category: male) }\end{array}$ & 1.19 & 0.90 to 1.57 & 1.52 & 0.94 to 2.46 \\
\hline \multicolumn{5}{|c|}{ Region (reference category: Central) } \\
\hline Atlantic & 0.48 & 0.32 to 0.71 & 1.13 & 0.41 to 3.15 \\
\hline Bogota & 1.51 & 1.01 to 2.25 & 2.48 & 0.75 to 8.16 \\
\hline Oriental & 0.98 & 0.65 to 1.48 & 1.10 & 0.61 to 1.98 \\
\hline Pacific & 1.36 & 0.92 to 2.00 & 1.03 & 0.58 to 1.83 \\
\hline \multicolumn{5}{|c|}{ Marital status (reference category=living with partner, married) } \\
\hline $\begin{array}{l}\text { Separated, widow, } \\
\text { divorced }\end{array}$ & 1.77 & 1.23 to 2.56 & 1.55 & 0.74 to 3.23 \\
\hline Single & 1.04 & 0.76 to 1.44 & 1.03 & 0.57 to 1.85 \\
\hline \multicolumn{5}{|c|}{ Other indicators of socioeconomic level } \\
\hline \multicolumn{5}{|c|}{ Educational level (reference category=no or primary education) } \\
\hline Secondary & 1.31 & 0.91 to 1.87 & 0.64 & 0.35 to 1.17 \\
\hline Technical & 1.02 & 0.56 to 1.84 & 0.17 & 0.03 to 1.10 \\
\hline University & 1.94 & 1.09 to 3.45 & $\mathrm{NA} \dagger$ & - to - \\
\hline \multicolumn{5}{|c|}{ Affiliation with the social security system $\neq$ (reference category=contributive) } \\
\hline Special & 0.75 & 0.37 to 1.54 & 0.38 & 0.05 to 2.91 \\
\hline Subsidised & 1.33 & 0.95 to 1.86 & 1.01 & 0.58 to 1.77 \\
\hline Not affiliated & 1.83 & 1.21 to 2.76 & 0.63 & 0.21 to 1.84 \\
\hline \multicolumn{5}{|c|}{ Other relevant variables for mental health } \\
\hline \multicolumn{5}{|c|}{ Family dysfunction (reference category: no family dysfunction) } \\
\hline Light & 1.56 & 0.99 to 2.46 & 1.39 & 0.72 to 2.70 \\
\hline Moderate & 1.73 & 1.13 to 2.64 & 3.29 & 1.72 to 6.32 \\
\hline Severe & 3.02 & 1.87 to 4.88 & 2.35 & 0.79 to 6.99 \\
\hline \multicolumn{5}{|c|}{ How often can you talk to someone about your problems or difficulties or ask for advice? (reference category=always) } \\
\hline Almost always & 1.44 & 0.91 to 2.27 & 0.54 & 0.25 to 1.15 \\
\hline Sometimes & 1.41 & 0.97 to 2.04 & 0.68 & 0.37 to 1.22 \\
\hline Never & 1.72 & 1.10 to 2.67 & 0.69 & 0.34 to 1.42 \\
\hline $\begin{array}{l}\text { Experience with armed } \\
\text { conflict (reference } \\
\text { category: no) }\end{array}$ & 1.97 & 1.19 to 3.26 & 1.65 & 0.82 to 3.33 \\
\hline
\end{tabular}

${ }^{*}$ Housing score results are RII, for other variables results are ORs, both with their respective $95 \% \mathrm{Cls}$.

†In rural areas, there were no participants with a university degree reporting mental disorders.

$\ddagger$ The contributive regime includes those in formal employment or independent jobs with economic capacity to pay a monthly fee; special regime includes armed forces, workers in the petroleum industry and teachers in the public sector; in the subsidised regime are those classified as 'poor' and their insurance fee is paid by the government and not affiliated are those without health insurance. NA, not applicable.

Table 6 shows that, within the rural population, individuals living in 'populated centres' (small towns, villages) had a higher lifetime prevalence of any mental health disorder $(9.8 \%, 95 \%$ CI 6.9 to 13.6$)$ compared with those living in a more isolated lifestyle in dispersed areas $(6.0 \%, 95 \%$ CI 4.6 to 7.7$)$.

We tested to see if these results were confounded by the consumption of alcohol. While there was an association 
Table 5 Slope index of inequality (SII) (based on housing score), in multivariate models for lifetime prevalence of any mental disorder

\begin{tabular}{|c|c|c|c|c|}
\hline & \multicolumn{2}{|l|}{ Urban } & \multicolumn{2}{|l|}{ Rural } \\
\hline & SII & $95 \% \mathrm{Cl}$ & SII & $95 \% \mathrm{Cl}$ \\
\hline $\begin{array}{l}\text { Housing score } \\
\text { Adjusted by age, sex, region and marital status }\end{array}$ & 0.010 & -0.035 to 0.056 & -0.094 & -0.151 to -0.037 \\
\hline $\begin{array}{l}\text { Housing score } \\
\text { Adjusted by age, sex, region, marital status, } \\
\text { educational attainment, affiliation to the social } \\
\text { security system, armed internal conflict, family } \\
\text { dysfunction and social support. }\end{array}$ & -0.002 & -0.055 to 0.050 & -0.121 & -0.184 to -0.058 \\
\hline
\end{tabular}

(in urban areas only) between problematic alcohol consumption and a lifetime prevalence of mental disorders, alcohol consumption patterns did not alter the association with the other study variables and therefore was not considered a confounder (online Supplementary table 2). We performed one additional analysis using the self-reporting questionnaire (SRQ) instead of the CIDI to measure anxiety and depression and all associations remained consistent with the previous results (online Supplementary table 3 ).

\section{DISCUSSION}

In this cross-sectional study, poorer housing characteristics were associated with (much) lower lifetime prevalence of depressive and anxiety disorders in rural areas of Colombia. In urban areas, prevalence was higher but not associated with housing characteristics. These findings are contrary to our expectations based on the literature, but the limited body of evidence in this field is almost exclusively based on data from urban settings in HIC and sampling frames from patients in clinics rather than households. This evidence largely shows positive associations between low socioeconomic status and mental health disorders, also in LMIC. ${ }^{1235}$ However, the few household-based findings reported from LMIC show weak, if any, associations between poverty (based on household consumption) or income inequalities and mental health; in Mexico, being poor, that is, in the bottom quartile of the household per capita consumption distribution, was related to lower levels of mental health problems. ${ }^{3}$ Another analysis, conducted in a rural district

Table 6 Prevalence of mental health disorder in rural areas, disaggregated by populated or dispersed area*

\begin{tabular}{lll}
\hline \multirow{2}{*}{$\begin{array}{l}\text { Type of area of the } \\
\text { household }\end{array}$} & \multicolumn{2}{l}{ Any mental health disorder (lifetime) } \\
\cline { 2 - 3 } & $\%$ & $\mathbf{9 5 \%} \mathbf{~ C l}$ \\
\hline $\begin{array}{l}\text { Populated centre } \\
\text { (rural) }\end{array}$ & 9.8 & 6.9 to 13.6 \\
$\begin{array}{l}\text { Dispersed rural } \\
\text { Difference }\end{array}$ & 6.0 & 4.6 to 7.7 \\
\hline
\end{tabular}

*Populated centres are small towns, villages while dispersed areas (within rural settings) are defined as isolated houses. of Kenya, found no associations between mental disorders and different SEP measures: education, employment and housing characteristics ${ }^{36}$; similar findings were observed in Ghana. ${ }^{8}$ All findings consistently report that changes in living circumstances likely have a larger impact on mental health than the absolute levels of poverty or low SEP. In Colombia, experience with the armed conflict probably caused important changes for many households (eg, internal migration mostly towards larger cities) and in our analyses was positively associated with a higher prevalence of mental health problems.

There is likely a complex interplay of different social, economic and diagnostic factors involved in these differences in the observed associations between socioeconomic class and mental health in urban versus rural populations. Perception of one's own socioeconomic status compared with others' may be more related to mental health than absolute socioeconomic status. ${ }^{1312}$ In areas with a relatively homogeneous socioeconomic strata, as is likely the case in rural dispersed areas of Colombia, socioeconomic status was not always clearly associated with mental health problems. ${ }^{1237-39}$ Explanations include a higher tolerance of high income inequality, lower expectations of equality or a lack of awareness of inequality because communities are so segregated. ${ }^{140}$ In urban areas, the distribution of SES is very heterogeneous and comparing one's own status with that of someone better-off may increase the likelihood of developing mental health problems in the future. $^{312}$

Additionally, in rural areas, having excellent mental health status may not be a requirement for reasonable social and financial functioning for most of the population. Among highly trained professionals, mental health is increasingly important for functioning-which may be why we observe more anxiety and depression in the highest socioeconomic classes (those with the best housing quality). Among the lower socioeconomic groups, existing mental health problems may express themselves differently (somatisation or dissociative disorders) or may go undiagnosed-either because of a lack of diagnostic capacity or because the mental health problems do not have a strong impact on individuals' functioning. In urban areas, with a service economy, poor mental health may have a greater impact on daily functioning. The 
wealthier part of the urban population has better material and immaterial (cultural capital, prestige, influential relationships, etc) resources to adapt to these demands, which in the long term may cause a negative association between socioeconomic position and mental health. In Colombian cities, we may be observing a process of transition-from the 'inverse' association observed in the countryside and the negative association in cities in high-income countries-which may explain the lack of association observed in Colombian urban populations.

Individuals living in areas undergoing rapid urbanisation processes are known to develop more mental health problems. ${ }^{41-43}$ This is in line with our observations of a higher prevalence of mental health problems in urban areas, and the lowest prevalence of mental health disorders in populations with the poorest housing scores in the countryside, and in dispersed rural areas, both indicators of very low levels of urbanisation. This might indicate that the housing index used in this analysis is actually closer to an urbanisation index, which might partially explain our findings. If that is the case, we could have an example of confounding urbanisation and SEP. This should be taken into account in future analyses in LMIC settings where housing conditions could reflect both the ongoing processes of urbanisation and household SEP living conditions.

Colombia's urbanisation process develops rapidly and is largely unplanned. In urban populations in India and Nepal, multiple effects of unplanned urbanisation (fast population growth, environmental degradation and sociocultural conflicts) are possible contributors to an increasing prevalence of depression and anxiety. ${ }^{42}{ }^{43} \mathrm{~A}$ higher prevalence of mental health disorders in urban environments may also result from the tendency of some mentally ill people to settle in towns rather than in the countryside. $^{44}$

The literature on the relationship between mental health and socioeconomic status is mostly based on data from HIC, and this association may be weaker in LMIC. It is thought that mental health disorders make it more difficult for individuals to keep regular working hours, and in HIC individuals with depression are more likely to become unemployed. ${ }^{45}{ }^{46}$ Colombia, like many LMIC, has a large informal sector, and the more flexible nature of employment, particularly in the informal sector and in agricultural work, may cause less work-related perceptions of mental health problems. In addition, mental health problems may be less frequent because of the lack of work-related stress. Additionally, in rural areas, larger family and village social support systems may help in lowering the risk of developing mental health problems, ${ }^{3}$ and since poor rural communities may be isolated, individuals in these communities may be less aware of income inequalities and therefore may be mentally less affected by the poor living conditions. ${ }^{140}$

On the other hand, mental health problems may also present themselves differently in rural versus urban areas in LMIC. We observed known associations, for example, the association between problematic alcohol use and mental health problems, only in rural areas. Another example is the surprisingly high frequency of suicides in rural areas in Colombia-while the prevalence of mental health problems seems to be low. ${ }^{47-50}$ This implies that we should study ways in which mental problems might express themselves in rural populations in order to find ways to measure and diagnose such problems in these populations. Since associations remained consistent when using the SRQ instead of the CIDI to measure anxiety and depression, we believe that it was probably not the instrument that caused these observed associations. However, results may (partly) be explained by information bias because of different sensitivities in measuring anxiety and depression in urban versus rural populations, and it is also conceivable that both the SRQ and CIDI are not ideal for measuring mental health disorders in rural populations in LMIC.

The population-based nature of the survey data and the standardised instruments used are strengths of this study, which allowed us for the first time in a LMIC to study mental health in rural as well as urban settings. The main limitation of this study is the use of lifetime prevalence of mental health disorders: the relatively low individual prevalence by type of disorder and the low 12-month prevalence did not allow for analyses on those alternative outcomes. Additionally, although the present study was not intended to determine causation, but rather to identify associations, the cross-sectional nature of the data means that our findings on inequalities may be susceptible to health selection. The ENSM IV was designed to be nationally representative but that does not automatically imply that the urban and rural areas are completely representative. Nevertheless, considering the relatively large sample of urban and rural households in the different housing score categories and the very consistent findings, we believe our results indicate a very interesting and understudied phenomenon in mental health.

The observed differences in prevalence of mental health problems and patterns of inequalities between urban and rural settings should lead to different approaches by medical staff and decision-makers, as the lower reported prevalence and inverse gradients among the population living in houses of poorer quality may be either due to hidden existing, but differently expressed, problems in rural areas or may also be real and could underlie the low prevalence in some LMICs. ${ }^{51}$ Our housing score may be considered either an indicator of SEP or of urbanisation, and its use in this aspect merits further investigation. The progressive urbanisation process in Colombia calls for surveillance of mental health problems in the population migrating to the cities. Further understanding of the phenomenon of the association between urbanisation and poverty and mental health problems is needed, in particular in LMIC. 


\section{Author affiliations}

${ }^{1}$ Department of Clinical Epidemiology and Biostatistics, Pontificia Universidad Javeriana, Bogota, Colombia

${ }^{2}$ Department of Epidemiology, Erasmus MC University Medical Center, Rotterdam, The Netherlands

${ }^{3}$ Department of Public Health, Erasmus MC University Medical Center, Rotterdam, The Netherlands

${ }^{4}$ Department of Psychiatry and Mental Health, Hospital Universitario San Ignacio, Bogota, Colombia

${ }^{5}$ Departamento de Salud Colectiva, Facultad de Odontología, Universidad Naciona de Colombia, Bogota, Colombia

${ }^{6}$ Department of Epidemiology and Public Health, University College London, London, UK

Contributors EdV, CJR, NTM, MNR, CG-R and CCG-H were involved in the study design. EdV, NTM and CCG-H were involved in the drafting of text. EdV, NTM, MNR, JPM, CG-R and CCG-H interpreted the findings. CJR and MNR were responsible for the statistical analysis. CJR, JPM and CG-R critically reviewed the drafts. MNR and JPM gave text suggestions. HT was involved in the critical revision of manuscript and statistical advice.

Funding The planning and execution of the Colombian Mental Health Survey was funded by The Administrative Department of Science, Technology and Innovation 'COLCIENCIAS' and The Health and Social Welfare Ministry of Colombia under the grant 762-2013

Competing interests None declared.

Patient consent Not required.

Ethics approval Medical Ethical Committee of the Pontificia Universidad Javeriana, Hospital San Ignacio.

Provenance and peer review Not commissioned; externally peer reviewed.

Data sharing statement The original data of the encuesta de salud mental 2015 are available through a formal request to the Ministry of Health, free of charge.

Open Access This is an Open Access article distributed in accordance with the Creative Commons Attribution Non Commercial (CC BY-NC 4.0) license, which permits others to distribute, remix, adapt, build upon this work non-commercially, and license their derivative works on different terms, provided the original work is properly cited and the use is non-commercial. See: http://creativecommons.org/ licenses/by-nc/4.0/

(c) Article author(s) (or their employer(s) unless otherwise stated in the text of the article) 2018. All rights reserved. No commercial use is permitted unless otherwise expressly granted.

\section{REFERENCES}

1. Maselko J. Social epidemiology and global mental health: expanding the evidence from high-income to low- and middle-income countries. Curr Epidemiol Rep 2017;4:166-73.

2. Lund C, Breen A, Flisher AJ, et al. Poverty and common mental disorders in low and middle income countries: a systematic review. Soc Sci Med 2010;71:517-28.

3. Das J, Do QT, Friedman J, et al. Mental health and poverty in developing countries: revisiting the relationship. Soc Sci Med 2007;65:467-80.

4. Kessler RC, Chiu WT, Demler O, et al. Prevalence, severity, and comorbidity of 12-month DSM-IV disorders in the National Comorbidity Survey Replication. Arch Gen Psychiatry 2005;62:617-27.

5. de Girolamo G, Polidori G, Morosini P, et al. Prevalence of common mental disorders in Italy: results from the European Study of the Epidemiology of Mental Disorders (ESEMeD). Soc Psychiatry Psychiatr Epidemiol 2006;41:853-61.

6. Meng X, Brunet A, Turecki G, et al. Risk factor modifications and depression incidence: a 4-year longitudinal Canadian cohort of the Montreal Catchment Area Study. BMJ Open 2017;7:e015156.

7. Jenkins R, Othieno C, Ongeri L, et al. Common mental disorder in Nyanza province, Kenya in 2013 and its associated risk factors - an assessment of change since 2004 , using a repeat household survey in a demographic surveillance site. BMC Psychiatry 2015;15:309.

8. Dzator J. Hard times and common mental health disorders in developing countries: insights from urban Ghana. J Behav Health Serv Res 2013;40:71-87.
9. Andersson LMC, Twum-Antwi A, Staland-Nyman C, et al. Prevalence and socioeconomic characteristics of alcohol disorders among men and women in the Eastern Cape Province, South Africa. Health Soc Care Community 2018;26.

10. Dai J, Chiu HF, Conner KR, et al. Suicidal ideation and attempts among rural Chinese aged 16-34 years - socio-demographic correlates in the context of a transforming China. J Affect Disord 2011;130:438-46.

11. Lund C, De Silva M, Plagerson S, et al. Poverty and mental disorders: breaking the cycle in low-income and middle-income countries. Lancet 2011;378:1502-14.

12. Evans GW, Wells NM, Chan HY, et al. Housing quality and mental health. J Consult Clin Psychol 2000;68:526-30.

13. Peen J, Schoevers RA, Beekman AT, et al. The current status of urban-rural differences in psychiatric disorders. Acta Psychiatr Scand 2010;121:84-93.

14. Munhoz TN, Nunes BP, Wehrmeister FC, et al. A nationwide population-based study of depression in Brazil. J Affect Disord 2016;192:226-33.

15. Noorbala AA, Faghihzadeh S, Kamali K, et al. Mental health survey of the Iranian adult population in 2015. Arch Iran Med 2017;20:128-34.

16. Gómez-Restrepo C, de Santacruz C, Matallana D, et al. Encuesta nacional de salud mental 2015. Tomo I. Bogotá D.C. Colombia: Ministerio de Salud, COLCIENCIAS, 2015.

17. Gómez-Restrepo C, de Santacruz C, Rodriguez MN, et al. [Colombia 2015 national mental health survey. Study protocol]. Rev Colomb Psiquiatr 2016;45(Suppl 1):2-8.

18. Fonseca Z, Heredia A, Ocampo P, et al. Encuesta Nacional de La Situación Nutricional En Colombia 2010. 2011.

19. Ojeda G, Ordóñez M, Ochoa L. Salud sexual y reproductiva en Colombia. Encuesta nacional de demografía y salud. Bogota, Colombia: Profamilia, 2005.

20. Xavier M, Baptista H, Mendes JM, et al. Implementing the World Mental Health Survey Initiative in Portugal - rationale, design and fieldwork procedures. Int J Ment Health Syst 2013;7:19.

21. Workshop of Australian National Tax Centre. Size and measurement of the informal economy in 110 countries. ANU, Canberra: Workshop of Australian National Tax Centre, 2002.

22. Flórez C. The function of the urban informal sector in employment: evidence from Colombia 1984-2000. Colombia: Universidad de los Andes, 2002.

23. Howe LD, Galobardes B, Matijasevich A, et al. Measuring socioeconomic position for epidemiological studies in low- and middleincome countries: a methods of measurement in epidemiology paper. Int J Epidemiol 2012;41:871-86.

24. González C, Houweling TA, Marmot MG, et al. Comparison of physical, public and human assets as determinants of socioeconomic inequalities in contraceptive use in Colombia moving beyond the household wealth index. Int J Equity Health 2010;9:10.

25. The Equity Tool. http://www.equitytoo.org/methods/

26. Guerrero R, Gallego Al, Becerril-Montekio V, et al. [The health system of Colombia]. Salud Publica Mex 2011;53(Suppl 2):s144-55.

27. De Vries E, Meneses MX, Piñeros M. [Years of life lost as a measure of cancer burden in Colombia, 1997-2012]. Biomedica 2016;36:547-29.

28. Ariza L, Durán M, Cubillos $Z$, et al. Consistencia interna y análisis de factores de la escala APGAR para evaluar el funcionamiento familiar en estudiantes de básica secundaria. Rev Colomb Psiquiatr;35:23-9.

29. Lorant V, Deliège $D$, Eaton W, et al. Socioeconomic inequalities in depression: a meta-analysis. Am J Epidemiol 2003;157:98-112.

30. Sareen J, Afifi TO, McMillan KA, et al. Relationship between household income and mental disorders: findings from a populationbased longitudinal study. Arch Gen Psychiatry 2011;68:419-27.

31. Mackenbach JP, Stirbu I, Roskam AJ, et al. Socioeconomic inequalities in health in 22 European countries. $N$ Engl J Med 2008;358:2468-81.

32. Mackenbach JP, Kunst AE. Measuring the magnitude of socioeconomic inequalities in health: an overview of available measures illustrated with two examples from Europe. Soc Sci Med 1997;44:757-71.

33. Moreno-Betancur M, Latouche A, Menvielle G, et al. Relative index of inequality and slope index of inequality: a structured regression framework for estimation. Epidemiology 2015;26:518-27.

34. Royston P, White I. Multiple imputation by chained equations (MICE): implementation in Stata. J Stat Softw 2011;45:1-20.

35. lemmi V, Bantjes J, Coast E, et al. Suicide and poverty in low-income and middle-income countries: a systematic review. Lancet Psychiatry 2016;3:774-83.

36. Jenkins R, Njenga F, Okonji M, et al. Prevalence of common mental disorders in a rural district of Kenya, and socio-demographic 
risk factors. Int $J$ Environ Res Public Health 2012;9:1810-9.

37. Kebede D, Alem A. Major mental disorders in Addis Ababa, Ethiopia. I. Schizophrenia, schizoaffective and cognitive disorders. Acta Psychiatr Scand Suppl 1999;397:11-17.

38. Kebede D, Alem A. Major mental disorders in Addis Ababa, Ethiopia. II. Affective disorders. Acta Psychiatr Scand Suppl 1999;397:18-23.

39. Kebede D, Alem A. Major mental disorders in Addis Ababa, Ethiopia. III. Neurotic and somatoform disorders. Acta Psychiatr Scand Suppl 1999;397:24-9.

40. Cifuentes M, Sembajwe G, Tak S, et al. The association of major depressive episodes with income inequality and the human development index. Soc Sci Med 2008;67:529-39.

41. Harpham T, Blue I. Linking health policy and social policy in urban settings: the new development agenda. Trans $R$ Soc Trop Med Hyg 1997;91:497-8.

42. Risal A, Manandhar K, Linde M, et al. Anxiety and depression in Nepal: prevalence, comorbidity and associations. BMC Psychiatry 2016;16:102.

43. Trivedi JK, Sareen H, Dhyani M. Rapid urbanization - its impact on mental health: a south asian perspective. Indian J Psychiatry 2008;50:161-5.

44. Weich S, Twigg L, Lewis G. Rural/non-rural differences in rates of common mental disorders in Britain: prospective multilevel cohort study. Br J Psychiatry 2006;188:51-7.
45. Andreeva E, Magnusson Hanson LL, Westerlund H, et al. Depressive symptoms as a cause and effect of job loss in men and women: evidence in the context of organisational downsizing from the Swedish longitudinal occupational survey of health. BMC Public Health 2015;15:1045.

46. Olesen SC, Butterworth P, Leach LS, et al. Mental health affects future employment as job loss affects mental health: findings from a longitudinal population study. BMC Psychiatry 2013;13:144.

47. Fontanella CA, Hiance-Steelesmith DL, Phillips GS, et al. Widening rural-urban disparities in youth suicides, United States, 1996-2010. JAMA Pediatr 2015;169:466-73.

48. Cardona Arango D, Medina-Pérez ÓA, Cardona Duque DV. [Characterisation of suicide in Colombia, 2000 2010]. Rev Colomb Psiquiatr 2016;45:170-7.

49. Kapusta ND, Zorman A, Etzersdorfer E, et al. Rural-urban differences in Austrian suicides. Soc Psychiatry Psychiatr Epidemiol 2008;43:311-8

50. Handley TE, Inder KJ, Kelly BJ, et al. Urban-rural influences on suicidality: gaps in the existing literature and recommendations for future research. Aust J Rural Health 2011;19:279-83.

51. Demyttenaere K, Bruffaerts R, Posada-Villa J, et al. Prevalence, severity, and unmet need for treatment of mental disorders in the World Health Organization World Mental Health Surveys. JAMA 2004;291:2581-90. 